\title{
An assessment of heavy metal pollution in the East London and Port Elizabeth harbours
}

\author{
OS Fatoki* and S Mathabatha \\ Department of Chemistry, University of Fort Hare, Alice 5700, South Africa
}

\begin{abstract}
The distribution of heavy metals (zinc, cadmium, copper, iron, manganese and lead) was investigated in seawater and in sediment samples from the East London and Port Elizabeth harbours. Both are ports of major importance to the area. The aim was to assess the impact of potential pollution sources, mainly from the cities' formal disposal to the sea, from industry and from dockyard and shipping activities around the harbour. At the East London harbour, metal concentrations in sea water range from 0.2 to $72.0 \mathrm{mg} \cdot \ell^{-1}$ for $\mathrm{Cd}$, from 0.6 to $42.6 \mathrm{mg} \cdot \ell^{-1}$ for $\mathrm{Cu}$, from 2.4 to $183.0 \mathrm{mg} \cdot \ell^{-1}$ for $\mathrm{Fe}$, from 0.6 to $16.3 \mathrm{mg} \cdot \ell^{-1}$ for $\mathrm{Pb}$, from 0.9 to $23.9 \mathrm{mg} \cdot \ell^{-1}$ for $\mathrm{Mn}$ and from 0.5 to $27.6 \mathrm{mg} \cdot \ell^{-1}$ for $\mathrm{Zn}$. In sediments, metal concentrations using the total digestion method range from 0.12 to $1.63 \mathrm{mg} \cdot \mathrm{g}^{-1}$ (dry weight) for $\mathrm{Cd}, 12.7$ to $183.0 \mathrm{mg} \cdot \mathrm{g}^{-1}$ (dry weight) for $\mathrm{Cu}, 1046.0$ to $18114.0 \mathrm{mg} \cdot \mathrm{g}^{-1}$ (dry weight) for $\mathrm{Fe}$, 3.2 to $84.2 \mathrm{mg} \cdot \mathrm{g}^{-1}$ (dry weight) for $\mathrm{Pb}, 87.4$ to $549.0 \mathrm{mg} \cdot \mathrm{g}^{-1}$ (dry weight) for Mn, 26.1 to $332.0 \mathrm{mg} \cdot \mathrm{g}^{-1}$ (dry weight) for Zn. In the Port Elizabeth harbour, the concentration of metals in seawaters varied between $0.3 \mathrm{mg} \cdot \ell^{-1}$ and $4.0 \mathrm{mg} \cdot \ell^{-1}$ for Cd, between $0.5 \mathrm{mg} \cdot \ell^{-1}$ and $11.3 \mathrm{mg} \cdot \ell^{-1}$ for $\mathrm{Cu}$, between $3.7 \mathrm{mg} \cdot \ell^{-1}$ and $21.9 \mathrm{mg} \cdot \ell^{-1}$ for Fe, between $0.6 \mathrm{mg} \cdot \ell^{-1}$ and $4.2 \mathrm{mg} \cdot \ell^{-1}$ for Pb, between $0.7 \mathrm{mg} \cdot \ell^{-1}$ and $16.8 \mathrm{mg} \cdot \ell^{-1}$ for $\mathrm{Mn}$ and between $0.7 \mathrm{mg} \cdot \ell^{-1}$ and $16.2 \mathrm{mg} \cdot \ell^{-1}$ for $\mathrm{Zn}$. In sediments, values of metals also using the total digestion method ranged from 0.1 to $1.4 \mathrm{mg} \cdot \mathrm{g}^{-1}$ (dry weight) for $\mathrm{Cd}$, from 8.6 to $82.3 \mathrm{mg} \cdot \mathrm{g}^{-1}$ (dry weight) for $\mathrm{Cu}$, from 4219.0 to $15182.0 \mathrm{mg} \cdot \mathrm{g}^{-1}$ (dry weight) for $\mathrm{Fe}$, from 9.0 to $61.9 \mathrm{mg} \cdot \mathrm{g}^{-1}$ (dry weight) for $\mathrm{Pb}$, from 103.0 to $499.0 \mathrm{mg} \cdot \mathrm{g}^{-1}$ (dry weight) for $\mathrm{Mn}$ and from 18.8 to $126 \mathrm{mg} \cdot \mathrm{g}^{-1}$ (dry weight) for $\mathrm{Zn}$. The results are indicative of the contribution of heavy metal pollution from storm water drains and streams which carry runoff from industrial, urban and residential sources. Ship repair activities are also suspected to be responsible for elevated concentrations in the upper reaches of the harbour.
\end{abstract}

\section{Introduction}

The sea, and more particularly the aquatic systems (e.g. estuaries), are the ultimate respository of man's wastes. The highly dynamic nature of the marine environment allows for very rapid assimilation of these materials by processes such as dilution, dispersal, oxidation, degradation or sequestration into sediments. However, the capacity for such assimilation is limited. Understanding this process of 'absorption' by the oceans and thereby determining their 'assimilative capacities' has been the main challenge of marine pollution research during the last few decades. There is little doubt that significant successes have been achieved in reducing the contamination of our natural waters. However, these gains have in part been offset by the increasing number and total volume of marine discharges. This situation arises from the increasing individual demands for a higher standard of living (Lord, 1989).

A previous general programme for marine pollution monitoring along the coast of South Africa has been described in detail (Cloete and Watling, 1981). The aims of this programme were to discover and monitor resources of marine pollution, to establish coastal monitoring stations and to institute a national data centre where all the information from the current studies can be stored and utilised most effectively. The identification and continued monitoring of the effects of industrial and urban coastal developments is necessary if indigenous flora and fauna are to be protected (Watling and Watling, 1983).

The influx of pollutants to the oceans in the Southern Hemisphere can be expected to be considerably lower than that in the heavily industrialised Northern Hemisphere. However, the 3 000-km long

\footnotetext{
* To whom all correspondence should be addressed. 푱(040) 602-2011; fax (040) 653-1643; e-mail: Fatoki@ufh.ac.za Received 8 May 2000; accepted in revised form 18 December 2000.
}

southern coastline is becoming increasingly pressurised with new towns and industries. This increase in urbanisation and industrialisation leads to an increase of marine discharges and, therefore, the total load of pollutants being delivered to the sea (McGlashan, 1989). These discharges may contain heavy metals among other pollutants.

Through the natural process of biomagnification, minute quantities of metals become part of the various food chains and concentrations become elevated to levels which can prove to be toxic to both human and other living organisms (Ackefors, 1971; Bryan, 1971). The surface water is a medium which is commonly used for heavy metal pollution assessment. However, pollutant concentrations in sediments and water organisms provide a more stable means of obtaining an indication of the state of the associated water. Sediment profiles often uniquely preserve the historical sequence of pollution. One of the most important issues regarding the presence of contaminants in sediments in aquatic environments, according to Forstner (1978) is the potential availability of the contaminants in the sediments for aquatic life.

Heavy metals are stable and persistent environmental contaminants of coastal waters and sediments. Interest in metals like $\mathrm{Zn}, \mathrm{Cu}, \mathrm{Fe}$ and $\mathrm{Mn}$, which are required for metabolic activity in organisms, lies in the narrow "window" between their essentiality and toxicity. Others heavy metals like $\mathrm{Cd}, \mathrm{Hg}, \mathrm{Cr}$ and $\mathrm{Pb}$, may exhibit extreme toxicity even at low levels under certain conditions, thus necessitating regular monitoring of sensitive aquatic environments (Peerzada et al., 1990).

Several methods have been described for the determination of heavy metals in marine environments. These include graphite furnace-AAS (Burguera et al., 1995), flame-AAS (Dapaah et al., 1999; Gomez-Ariza et al., 1999), atomic fluorescence spectrometry (Cheam et al., 1992), anodic stripping voltammetry (Fischer and Van den Berg, 1999; Morales et al., 1999), ICP-AES (Hiraide et al., 


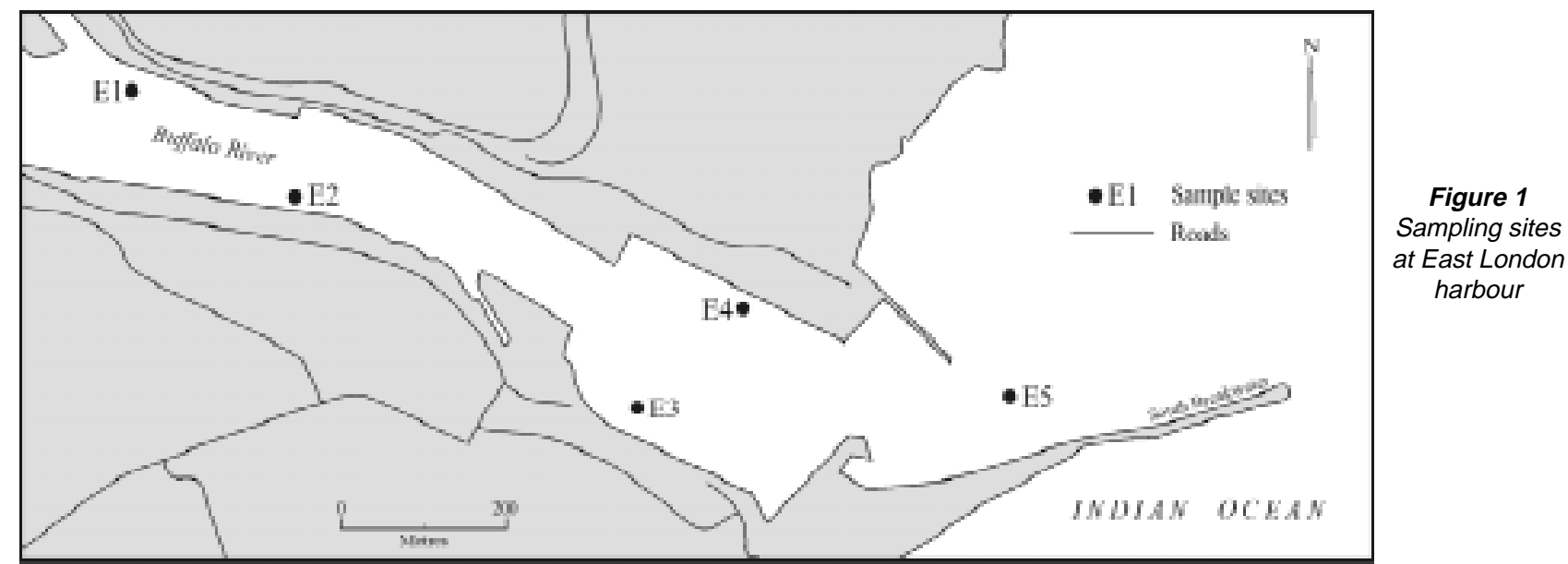

\begin{tabular}{|l|c|c|}
\hline \multicolumn{3}{|c|}{$\begin{array}{c}\text { TABLE 1 } \\
\text { Percentage recoveries of elements from spiked } \\
\text { water and sediment samples }\end{array}$} \\
\hline Element & $\begin{array}{c}\text { \% Recovery from } \\
\text { spiked seawater } \\
\text { samples }\end{array}$ & $\begin{array}{c}\text { \% Recovery from } \\
\text { spiked sediment } \\
\text { samples }\end{array}$ \\
\hline $\mathbf{C d}$ & $93.6 \pm 0.3$ & $94.8 \pm 0.3$ \\
$\mathbf{C u}$ & $93.6 \pm 0.2$ & $92.9 \pm 0.2$ \\
$\mathbf{P b}$ & $95.5 \pm 0.3$ & $96.9 \pm 0.2$ \\
$\mathbf{Z n}$ & $96.0 \pm 0.2$ & $94.1 \pm 0.1$ \\
$\mathbf{M n}$ & $94.9 \pm 0.2$ & $98.7 \pm 0.1$ \\
$\mathbf{F e}$ & $95.0 \pm 0.1$ & $92.4 \pm 0.2$ \\
\hline \multirow{2}{*}{$*$ Average of five replicate analyses \pm standard deviation } \\
\hline
\end{tabular}

1980) and ICP-MS (Ridout et al., 1988; Sakao et al., 1999).

This year-long study reports the results of a survey of heavy metals in water and sediments samples taken from East London and Port Elizabeth harbours using the extractive concentration techniques and flame AAS. This study was undertaken because of paucity of published data on heavy metal contamination in the two harbours.

\section{Sampling and sample location}

The sampling points are shown in Figs. 1 and 2 for the East London and Port Elizabeth harbours, respectively. All the sampling sites were identified by adjacent Bollard numbers.

\section{Materials and methods}

About $2.5 \ell$ water samples were collected at a distance of approximately $20 \mathrm{~m}$ from the quay at each sampling site. Before sampling, sample bottles were cleaned by washing them with detergent and then soaking them in $50 \% \mathrm{HCl}$ for $24 \mathrm{~h}$. Finally, the bottles were washed with water and then rinsed with triple-distilled water. Bottles were kept in 1\% nitric acid (Analytical Grade) before their use. Pre-cleaned high-density glass bottles were used for taking water samples, which were acidified on site with $5 \mathrm{~m} \ell \mathrm{HNO}_{3}$. Core sediment samples were collected by divers at the same site that was used for water samples. Both sample types were kept in ice before

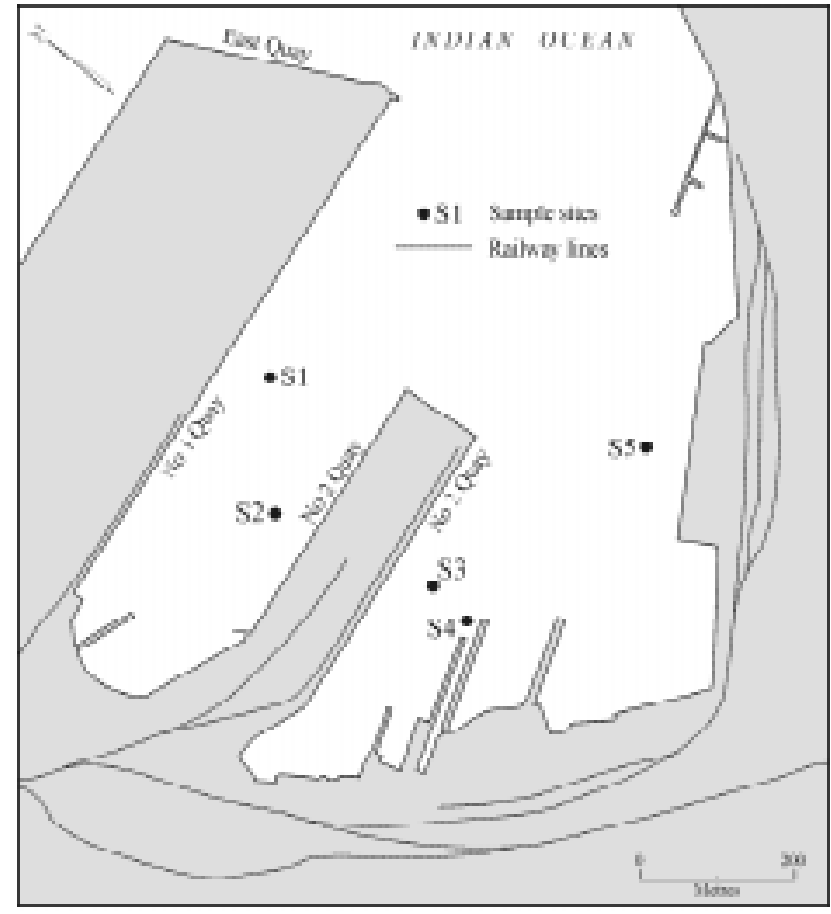

Figure 2

Sampling sites at the Port Elizabeth harbour

being transported to the laboratory for analysis. At the laboratory, sediments were freeze-dried for $24 \mathrm{~h}$. Thereafter they were placed on a filter-disc between sheets of filter paper and left to dry at room temperature.

\section{Analyses of water samples}

Water samples were filtered through a $0.45 \mathrm{~mm}$ Whatman no 1 filter paper. $100 \mathrm{~m} \ell$ of water sample was adjusted to $\mathrm{pH} 3.5$ with $\mathrm{HCl}$. The solution was transferred to a separatory funnel. $10 \mathrm{~m} \ell$ of a freshly prepared $2 \%$ solution of amino-pyrolidine dithiocarbamate (APDC) was added, and the mixture was shaken by a mechanical shaker. $20 \mathrm{~m} \ell$ of methyl-isobutyl-ketone was added and the mixture was again shaken for $2 \mathrm{~min}$. The phases were allowed to separate. The organic phase was separated and analysed using a Pye Unicam SP 939/959 AAS. Triplicate samples were extracted and analysed with the spectrophotometer. A blank determination 
was done using the same procedure but without water samples.

\section{Analyses of sediments}

Sediment samples were analysed using the "total digestion" method. $0.5 \mathrm{~g}$ sediment was weighed into a $100-\mathrm{m} \ell$ beaker. $5 \mathrm{~m} \ell$ of concentrated $\mathrm{HNO}_{3}$ was added and this was boiled gently for $30 \mathrm{~min}$ on a hot-plate. The beaker was cooled and $2 \mathrm{~m} \ell \mathrm{HClO}_{4}, 5 \mathrm{~m} \ell$ concentrated $\mathrm{HNO}_{3}$ and $5 \mathrm{~m} \ell \mathrm{HF}$ were added. The mixture was heated to near dryness. The corners and walls of the beakers were washed with about $5 \mathrm{~m} \ell$ triple-distilled water, and the solution was again heated until dense white fumes developed. The beaker was cooled and $10 \mathrm{~m} \ell \mathrm{HNO}_{3}$ was added to dissolve the salts. The solution was transferred into a $50 \mathrm{~m} \ell$ standard flask and then diluted with triple-distilled water. The solution was analysed by means of AAS. Triplicate samples were extracted and analysed with the spectro-photometer. A blank determination using the same procedure was performed.

\section{Quality assurance}

The spiking method was used for quality assurance tests because of the absence of reference materials. About $1 \mathrm{mg}$ each of $\mathrm{Zn}$ as zinc metal, of $\mathrm{Cu}$ as $\mathrm{Cu}\left(\mathrm{NO}_{3}\right)_{2}$, of $\mathrm{Pb}$ as $\mathrm{Pb}\left(\mathrm{NO}_{3}\right)_{2}$, of $\mathrm{Cd}$ as cadmium metal, of $\mathrm{Fe}$ as $\mathrm{Fe}_{2} \mathrm{O}_{3}$ and of $\mathrm{Mn}$ as $\mathrm{MnSO}_{4} \cdot \mathrm{H}_{2} \mathrm{O}$ were added to the weighed sample. The mixture in each case was subjected to the same analysis protocol as that adopted for seawater and sediments respectively, and the recovery of the added elements was determined. Five replicate addition experiments were performed for both seawater and sediment.

\section{Statistical methods}

Annual mean results at each site were calculated. The linear correlation coefficients of the elements in the samples were determined using the Pearson correlation coefficients:

$$
R^{2}=\frac{S x_{i} y_{i}-S x_{i} S y_{i}}{\left[S x_{i}^{2}-\left(S x_{i}\right)\right]\left[n S y_{i}^{2}-\left(S y_{i}\right)^{2}\right]}
$$

\section{Results}

The results of the quality assurance studies are shown in Table1 for both water samples and sediments. Percentage recoveries of the elements from spiked seawater samples ranged from 93.6 to $96.0 \%$ and from 92.4 to $98.7 \%$ from spiked sediments.

The heavy metal concentrations in water samples and sediments collected from East London and Port Elizabeth habours are listed in Figs. 3 to 14 . Water and sediment samples

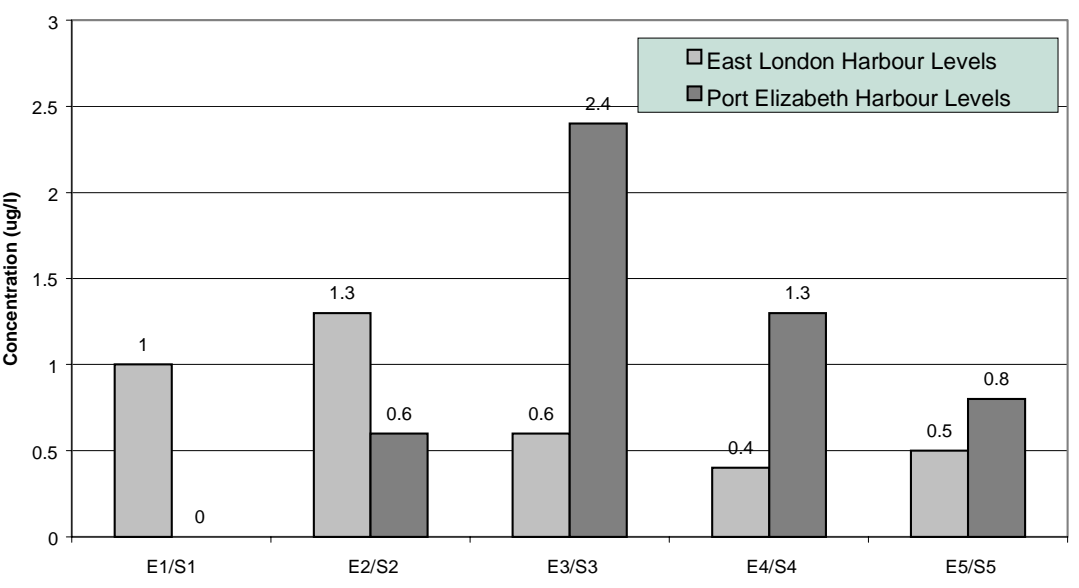

Figure 3

Annual mean concentrations of cadmium from water at East London and Port Elizabeth harbours (April 1999 - March 2000)

(Sampling from Port Elizabeth harbour started in May 1999 till March 2000 for all the elements)

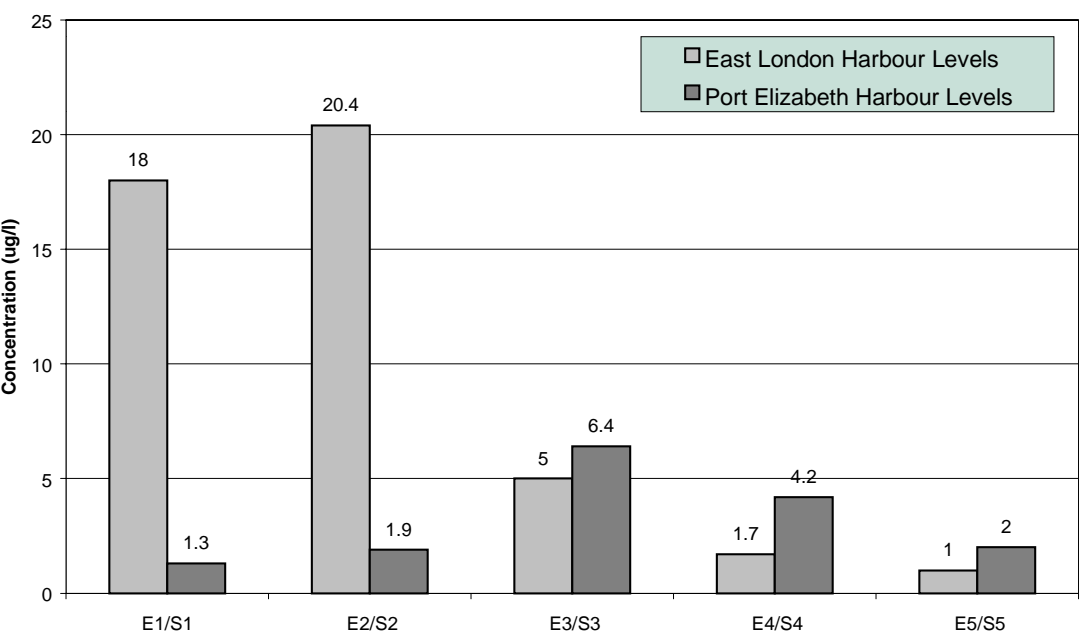

Figure 4

Annual mean concentrations of copper from water at East London and Port Elizabeth harbours (April 1999 - March 2000)

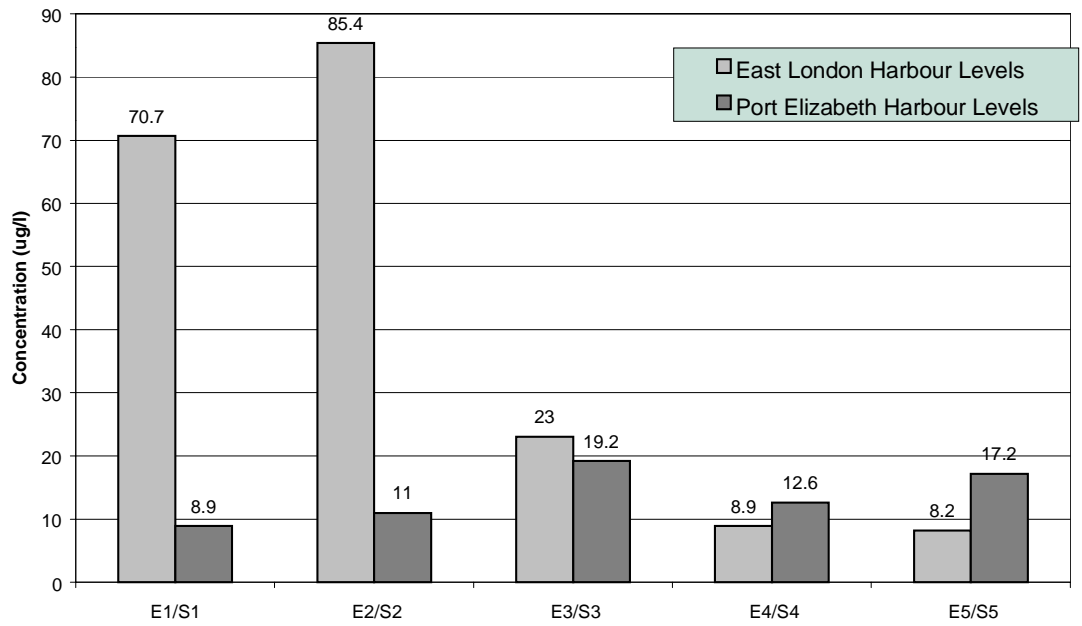

Figure 5

Annual mean concentrations of iron from water at East London and Port Elizabeth harbours (April 1999 - March 2000) 


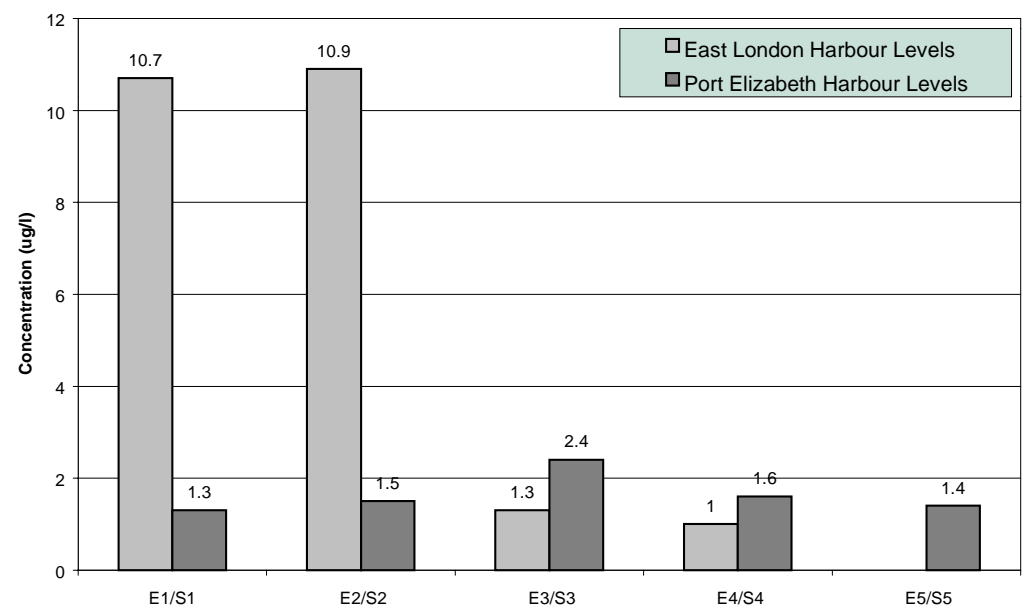

Figure 6

Annual mean concentrations of lead from water at East London and Port Elizabeth harbours (April 1999 - March 2000)

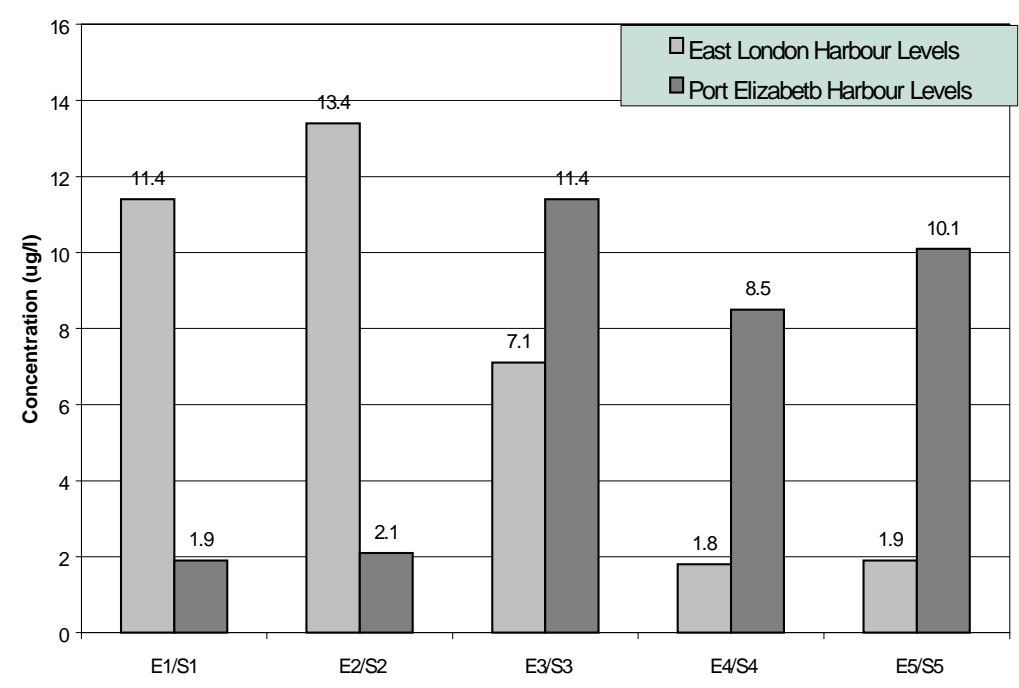

Figure 7

Annual mean concentrations of manganese from water at East London and Port Elizabeth harbours (April 1999 - March 2000)

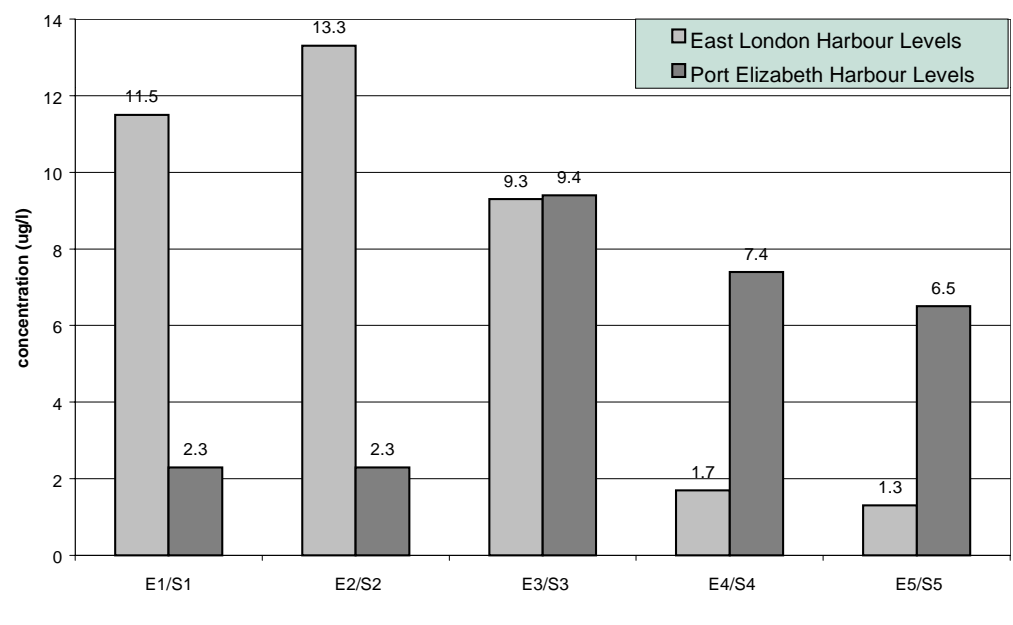

Figure 8

Annual mean concentrations of zinc from water at East London and Port Elizabeth harbours(April 1999 - March 2000) collected from sites E1 and E2 at East London harbour contained higher levels of metals compared to the other sites. Levels of metals in water samples at Site E1 ranged from 0.6 to $1.4 \mathrm{mg} \cdot \ell^{-1}$ for $\mathrm{Cd}$, from 6.8 to $36.9 \mathrm{mg} \cdot \ell^{-1}$ for $\mathrm{Cu}$, from 29.8 to $128.0 \mathrm{mg} \cdot \ell^{-1}$ for Fe, from 5.8 to 14.3 $\mathrm{mg} \cdot \ell^{-1}$ for $\mathrm{Pb}$, from 4.8 to $18.1 \mathrm{mg} \cdot \ell^{-1}$ for $\mathrm{Mn}$ and from 4.8 to $22.1 \mathrm{mg} \cdot \ell^{-1}$ for $\mathrm{Zn}$. Metals levels at Site E2 varied between $0.7 \mathrm{mg} \cdot \ell^{-1}$ and $2.7 \mathrm{mg} \cdot \ell^{-1}$ for $\mathrm{Cd}$, between $8.7 \mathrm{mg} \cdot \ell^{-1}$ and $42.6 \mathrm{mg} \cdot \ell^{-1}$ for $\mathrm{Cu}$, between $28.6 \mathrm{mg} \cdot \ell^{-1}$ and $183.0 \mathrm{mg} \cdot \ell^{-1}$ for $\mathrm{Fe}$, between $4.9 \mathrm{mg} \cdot \ell^{-1}$ and $18.8 \mathrm{mg} \cdot \ell^{-1}$ for $\mathrm{Pb}$, between $6.6 \mathrm{mg} \cdot \ell^{-1}$ and $23.9 \mathrm{mg} \cdot \ell^{-1}$ for $\mathrm{Mn}$ and between 4.62 $\mathrm{mg} \cdot \ell^{-1}$ and $27.6 \mathrm{mg} \cdot \ell^{-1}$ for $\mathrm{Zn}$. Levels of metals in sediment at Site E1 ranged from 0.3 to $1.6 \mathrm{mg} \cdot \mathrm{g}^{-1}$ for $\mathrm{Cd}$, from 219 to $85.8 \mathrm{mg} \cdot \mathrm{g}^{-1}$ for $\mathrm{Cu}$, from 10095.0 to $14603.0 \mathrm{mg} \cdot \mathrm{g}^{-1}$ for $\mathrm{Fe}$, from 10.4 to $80.2 \mathrm{mg} \cdot \mathrm{g}^{-1}$ for $\mathrm{Pb}$, from 109.0 to $357.0 \mathrm{mg} \cdot \mathrm{g}^{-1}$ for $\mathrm{Mn}$ and from 38.3 to $142.0 \mathrm{mg} \cdot \mathrm{g}^{-1}$ for $\mathrm{Zn}$. Metal levels at Site E2 ranged from 0.5 to $2.3 \mathrm{mg} \cdot \mathrm{g}^{-1}$ for $\mathrm{Cd}$, from 53.5 to $183.0 \mathrm{mg} \cdot \mathrm{g}^{-1}$ for $\mathrm{Cu}$, from 13 897.0 to $18114.0 \mathrm{mg} \cdot \mathrm{g}^{-1}$ for $\mathrm{Fe}$, from 21.6 to 56.3 $\mathrm{mg} \cdot \mathrm{g}^{-1}$ for $\mathrm{Pb}$, from 297 to $549.0 \mathrm{mg} \cdot \mathrm{g}^{-1}$ for $\mathrm{Mn}$ and from 38.3 to $142.0 \mathrm{mg} \cdot \mathrm{g}^{-1}$ for $\mathrm{Zn}$.

At Port Elizabeth harbour, Site 3 contained the highest levels of metals in samples. Levels of metals at this site in seawater varied between 1.0 $\mathrm{mg} \cdot \ell^{-1}$ and $4.0 \mathrm{mg} \cdot \ell^{-1}$ for $\mathrm{Cd}$, between $2.2 \mathrm{mg} \cdot \ell^{-1}$ and $11.3 \mathrm{mg} \cdot \ell^{-1}$ for $\mathrm{Cu}$, between $6.9 \mathrm{mg} \cdot \ell^{-1}$ and 36.8 $\mathrm{mg} \cdot \ell^{-1}$ for $\mathrm{Fe}$, between 1.0 and $5.1 \mathrm{mg} \cdot \ell^{-1}$ for $\mathrm{Pb}$, between $4.2 \mathrm{mg} \cdot \ell^{-1}$ and $21.7 \mathrm{mg} \cdot \ell^{-1}$ for $\mathrm{Mn}$ and between $3.4 \mathrm{mg} \cdot \ell^{-1}$ and $16.2 \mathrm{mg} \cdot \ell^{-1}$ for $\mathrm{Zn}$. Levels of metals in sediments ranged from 0.3 to 1.4 $\mathrm{mg} \cdot \mathrm{g}^{-1}$ for $\mathrm{Cd}$, from 45.9 to $92.5 \mathrm{mg} \cdot \mathrm{g}^{-1}$ for $\mathrm{Cu}$, from 5419 to $9046 \mathrm{mg} \cdot \mathrm{g}^{-1}$ for $\mathrm{Fe}$, from 29.5 to 61.9 $\mathrm{mg} \cdot \mathrm{g}^{-1}$ for $\mathrm{Pb}$, from 183.0 to $441.0 \mathrm{mg} \cdot \mathrm{g}^{-1}$ for $\mathrm{Mn}$ and from 73.8 to $126.0 \mathrm{mg} \cdot \mathrm{g}^{-1}$ for $\mathrm{Zn}$.

\section{Discussion}

The high percentage recoveries obtained (Table 1) from the quality assurance tests validated the analytical extraction procedures used for this study.

The metal concentrations at the East London harbour can be related to non-point source inflows from the four stormwater/streams discharging from urban/industrial areas around the harbour. The high concentration of metals at Sites E1 and E2 might be due to the contribution of the Buffalo River discharging into the harbour area at around these sites. The river is a recipient of domestic wastes from King Williams Town and from several informal settlements downstream. The high concentrations of metals at Site E1 (dry-dock area) might also be attributed to harbour activities such as stripping and painting of ships. Site E4 contained the highest concentrations of metals of all the sites. Apart from the fact that this site is close to motor scrap points, the source of the metal pollution might also be from run-of from a large motor assembly plant which lies upstream of the port. 
The quality standards for marine water under the EEC directives (Metocean, 1993; AURIS, 1994) and according to the Australian and New Zealand Environment and Conservation Council (ANZECC) guidelines (ANZECC, 1992) are shown in Table 2. The open ocean concentrations are estimated in the ranges 0.0001 to $0.12 \mathrm{mg} \cdot \ell^{-1}$ for $\mathrm{Cd}, 0.001$ to $0.04 \mathrm{mg} \cdot \ell^{-1}$ for $\mathrm{Pb}, 0.03$ to $04 \mathrm{mg} \cdot \ell^{-1}$ for $\mathrm{Cu}$, and 0.003 to $0.6 \mathrm{mg} \cdot \ell^{-1}$ for $\mathrm{Zn}$ (Bruland, 1980; Bruland and Franks,1983; Bruland et al., 1991). The metal concentrations in this study were higher than estimated open ocean concentrations. $\mathrm{Pb}$ and $\mathrm{Cu}$ concentrations at sites $\mathrm{E} 1$ and $\mathrm{E} 2$ were, however, lower than the EEC standards, but higher than the ANZECC standards. $\mathrm{Zn}$ and $\mathrm{Cd}$ concentrations were lower than both the ANZECC and EEC standards. There are no quality criteria given for $\mathrm{Fe}$ and $\mathrm{Mn}$. Metal concentrations at other sites are lower than the ANZECC and EEC standards.

Possible metal-metal relationships were investigated using the the statistical Pearson correlation coefficient, $\mathrm{r}$, at $\mathrm{a}=0.05$ significant level. At Sites E1 and E2, Cu, Zn, Cd and Mn are significantly correlated with values of $r$, varying between 0.74 and 0.90 at Site 1 and between 0.79 and 0.98 at Site 4 for the metals. These significant correlations of metals are indicative of a common source of pollution in the water.

The proposed South African (SA) guidelines limits for metals in sediments are also shown in Table 2. These guidelines were used by Maritz and Swanepoel in the interpretation of their results on dredged silt (1998). The Canadian Environmental Protection Authority (EPA) standards for metal levels (EPA, 1976) are indicated in the same table. Again no guidelines were given for $\mathrm{Fe}$ and $\mathrm{Mn}$. $\mathrm{Cd}$ and $\mathrm{Cu}$ levels found in this study were less than the above-mentioned guidelines at all sites. $\mathrm{Pb}$ levels are generally lower than SA guideline but higher than the EPA standards, except at $\mathrm{E} 1$ where the $\mathrm{Pb}$ levels were also lower than the EPA standards. Zn levels were lower than the SA guideline, but higher than the EPA standards at all sites.

At the Port Elizabeth harbour, Cd levels in seawater are lower than the EEC standards at all sites but higher than the ANZECC standards at Site S3. Cu levels are also higher than the EEC and the ANZECC standards at S3 but lower than these standards at other sites. Metal contamination at S3 might be due to docking activities at this site. $\mathrm{Pb}$ and $\mathrm{Zn}$ levels are normal at all sites compared with EEC and ANZECC standards. In sediments, while Cd levels are below the SA and the EPA standards, $\mathrm{Cu}$ concentrations are higher than the EPA standards at all the sites. Also, while $\mathrm{Pb}$ and $\mathrm{Zn}$ levels were lower than the SA guidelines at all the sites, they were higher than EPA standards except at sites $\mathrm{S} 1$ and $\mathrm{S} 2$ where the $\mathrm{Pb}$ levels were lower. Generally, there are no marked difference in the degree of metal pollution in the two harbours. Although, metal contamination of the two harbours

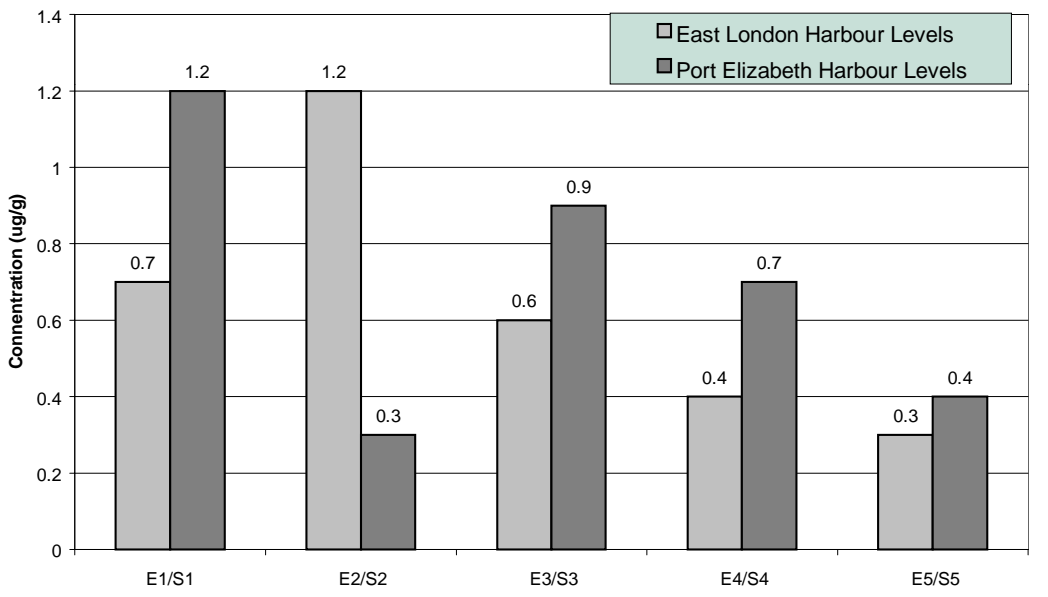

Figure 9

Annual mean (dry weight) concentrations of cadmium from sediment at East London and Port Elizabeth harbours (April 1999 - March 2000)

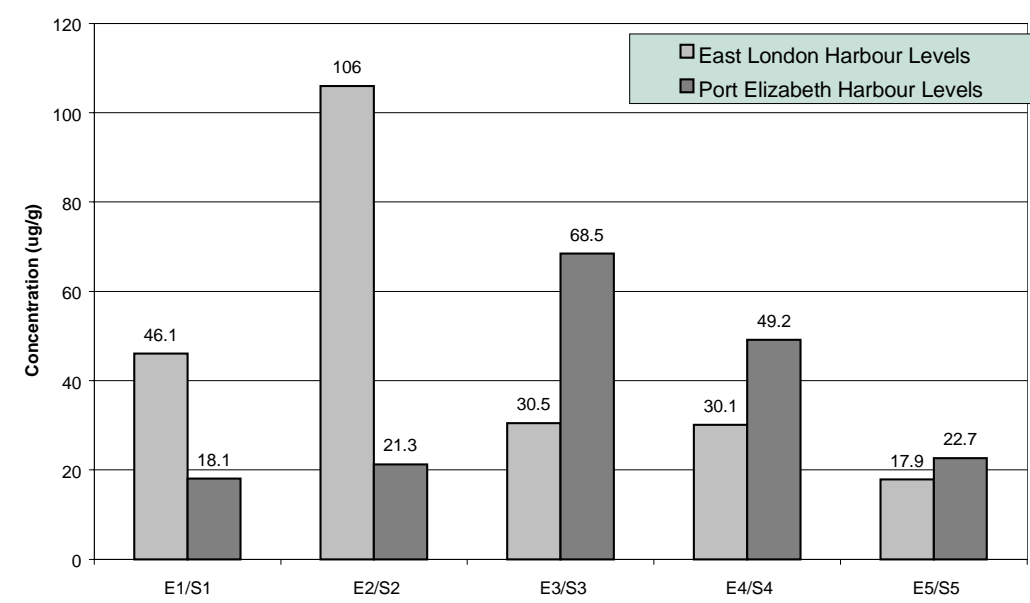

Figure 10

Annual mean (dry weight) concentrations of copper from sediment at East London and Port Elizabeth harbours (April 1999 - March 2000)

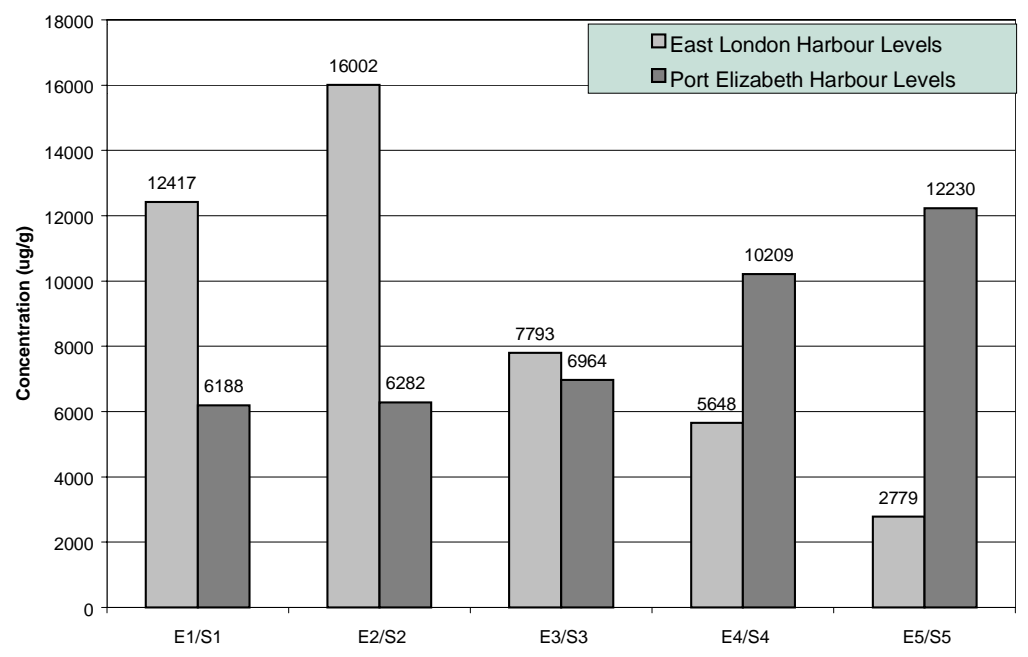

Figure 11

Annual mean (dry weight) concentrations of iron from sediment at East London and Port Elizabeth habours (April 1999 - March 2000) 

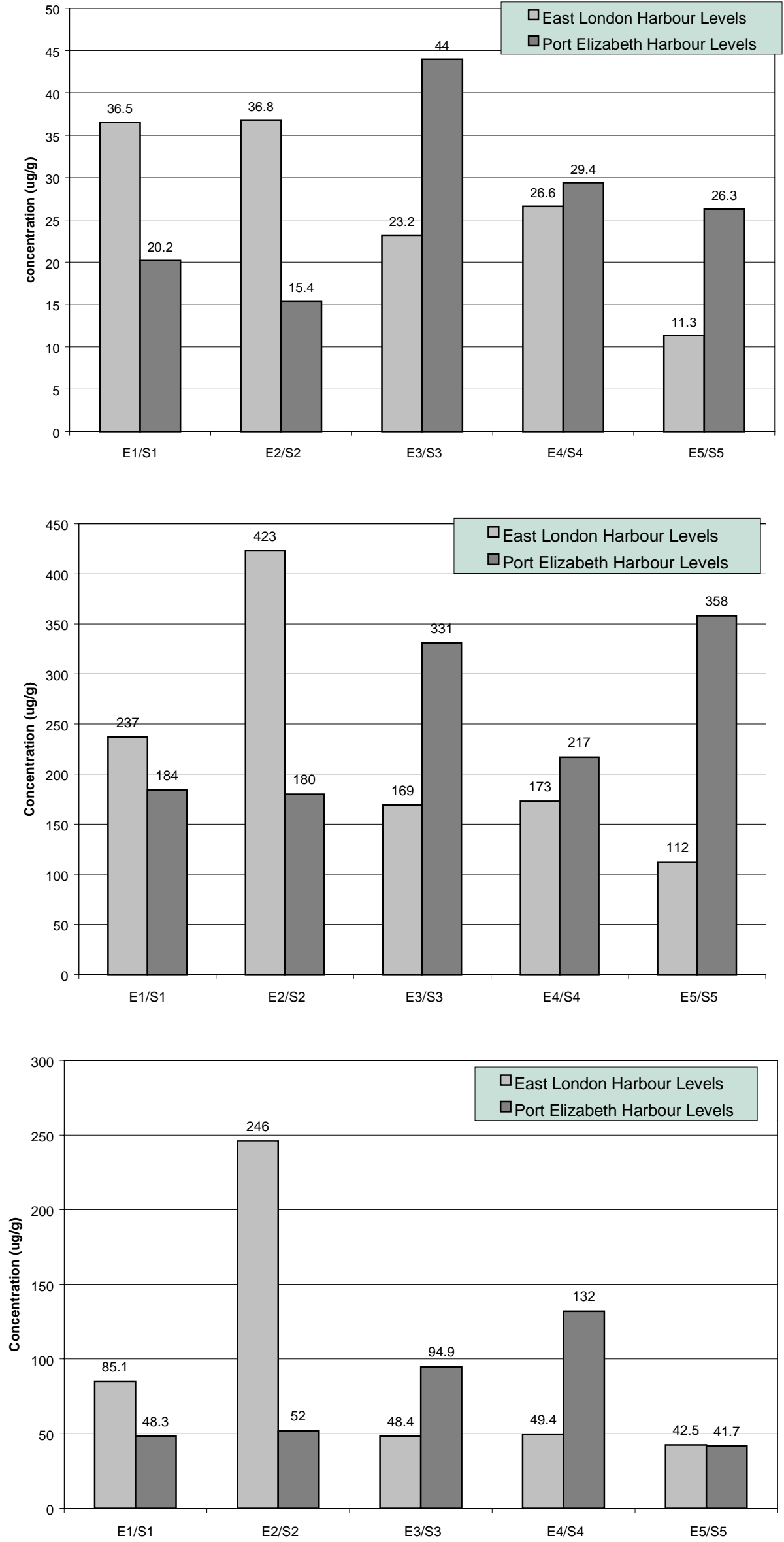

Figure 12

Annual mean (dry weight) concentrations of lead from sediment at East London and Port Elizabeth habours (April 1999 - March 2000)

Figure 13

Annual mean (dry weight) concentrations of manganese from sediment at East London and

Port Elizabeth harbours (April 1999 - March 2000)
Figure 14

Annual mean (dry weight) concentrations of zinc from sediment at East London and Port Elizabeth harbours (April 1999 - March 2000) 


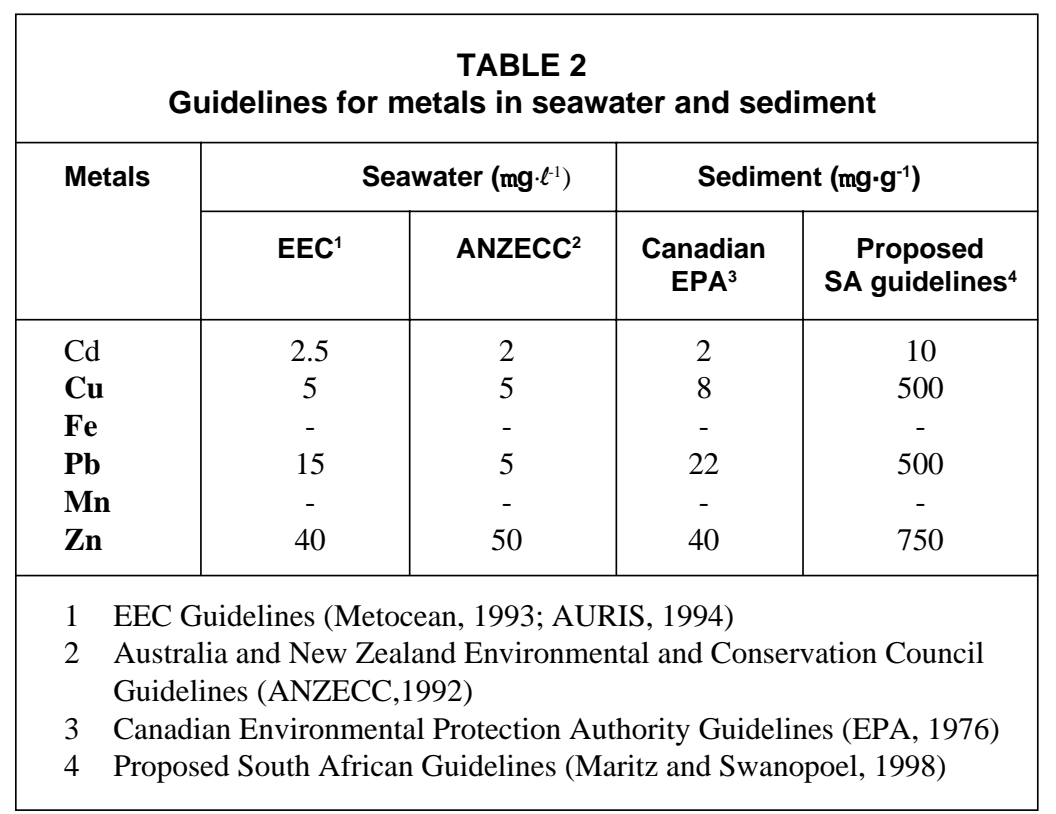

are indicated, the results showed that the levels have not exceeded limits. However, the situation needs close monitoring so that the safe limits are not exceeded because of the increasing activities at the ports. This may contribute to the degradation of the marine ecosystems in the harbours.

\section{Conclusion}

The metal concentrations in water and sediments from East London and Port Elizabeth harbour, though low, are indicative of pollution from point sources in and around the harbour and from diffuse sources such as urban runoff. However, the results also indicate that the levels have not exceeded the limits. The situation calls for regular monitoring so that the safe limits are not exceeded due to increased activities at the ports.

\section{Acknowledgement}

The authors will like to thank NRF for their financial support and Portnet (East London and Port-Elizabeth) for their assistance during the collection of samples.

\section{References}

ACKERFORS H (1971) Mercury pollution in Sweden with special reference to conditions in the water habitat. Proc. R. Soc. Lond. Ser. B 177 365.

ANZECC (1992) Australian Water Quality Guidelines for Fresh and Marine Waters, Australian and New Zealand Environment and Conservation Council.

AURIS (1994) Removal and disposal of Brent Spar: A safety environmental assessment of the options. Transport and transformations of petroleum: Biological processes. In: Bartha R and Atlas RM (eds.) Long-term Environmental Effects of Offshore Oil and Gas Development. Elsevier Applied Science, London and New York. 287 - 341.

BRULAND KW (1980) Oceanographic distribution of cadmium, zinc, nickel and copper in the North Pacific. Earth Planet Sci. Lett. 47 $176-198$.

BRULAND KW, DONATS JR and HUTCHINS DA (1991) Interactive influences of bioactive trace metals on biological production in oceanic waters. Limnol. Oceanogr. 361555 - 1577.
BRULAND KW and FRANKS PR (1983) Mn, Cu, Zn, and $\mathrm{Cd}$ in the Western North Atlantic. In: Wong CS, Boyl E, Bruland KW, Burton D and Goldberg ED (eds) Trace Elements in Seawater. NATOConference Series. $395-414$.

BRYAN GW (1971) The effects of heavy metal (other than mercury) on marine and estuarine organisms. Proc. R. Soc. Lond. Ser. B 177389.

BURGUERA M, BURGUERA JL, RIVAS C, CARREROP, BRUNETTO $\mathrm{R}$, and GALLIGNANI M (1995) Time-based device used for the determination of tin by hydride generation flow injection atomic absorption techniques. Anal. Chim. Acta 308339 - 356.

CHEAM V, LECHNER J, SEKERKA I, DESROSIERS R, NRIAGU J and LAWSON G (1992) Development of laser-excited atomic fluorescence spectrometer and a method for the direct determination of lead in Great Lake waters. Anal. Chim. Acta 269129 - 136.

CLOETE C E and WATLING RJ (1981) South African Marine Pollution Monitoring Programme 1979- 1982. Pretoria National Programme for Environmental Sciences, Report No. 51.

DAPAAH RK, TAKANO N and AYAME A (1999) Solvent extraction of $\mathrm{Pb}$ (II) from acid medium with zinc hexamethylenedithiocarbamate followed by back-extraction and subsequent determination by FAAS. Anal. Chim. Acta 386281 - 286.

EPA (1976) Heavy Metals in the Sediments of Port Phillip Bay and Input Streams. Environmental Protection Authority, Victoria. Report No. $16 / 76$.

FISCHER E and VAN DEN BERG CMG (1999) Anodic Stripping Voltammetry of $\mathrm{Pb}$ and $\mathrm{Cd}$ using a $\mathrm{Hg}$ film electrode and thiocyanate. Anal. Chim. Acta 385273 - 280.

FORSTNER U (1978) Sources and sediments associations of heavy metals in polluted coastal regions. In: Ahreus LH (eds.) On the Origin and Distribution of Elements. Proc. $2^{\text {nd }}$ Symp. Pergamon Press, Oxford.

GOMEZ-ARIZA JL, GIRALDEZ I, SANCHEZ-RHODES D and MORALES E (1999) Metal readsorption and re-distribution during analytical fractionation of trace elements in oxic estuarine sediments. Anal. Chim. Acta 399295 - 307.

HIRADE M, CHEN Z, SUGIMOTO K and KAWAGUCHI H (1980) Copreci-pitation with tin (IV) hyroxide followed by removal of tin carrier for the determination of trace heavy metals by graphite-furnace atomic absorption spectrometry. Anal. Chim. Acta 302103 - 107.

LORDDA (1989) South African coastal waters assimmilation or pollution? In: Moden AGS and Ridder JH (eds.) Marine Pollution - A 1988 Perspective. South African National Scientific Programe, Report No. 161. 2-10.

MARITZ NJ and SWANEPOOL JJ (1998) Chemical Analysis of Dredged Silt from Port Elizabeth Harbour. Laboratory Buiding, Braamfontein, Johannesburg Report No CL 41. 
McGLASHAN JE (1989) Charateristics of waste discharges. In: Moden AGS and Ridder JH (eds.) Marine Pollution - A 1988 Perspective. South African National Scientific Programme. Report No. 161. $11-20$.

METOCEAN PLC (1993) Evaluation of Environmental Aspects of the Deep water Disposal Option. Prepared for Shell UK. Exploration and Production Ltd. Report No 518.

MORALES MM, MART P, LIOPIS A, COMPOS L and SAGRADO S (1999) An environmental study by factor analysis of surface sea waters in the Gulf of Valencia (Western Mediterranean). Anal. Chim. Acta 394 (1) 109 - 117.

PEERZADA N, McMORROW L, SKILIROS S, GUINEA M and RYAN P (1990) Distribution of heavy metals in gove harbours. Sci. of Total Environ. 921 - 12.

PHILLPS DJL (1977) The use of biological indicator organisms to monitor trace metal pollution in marine and estuarine environment - A review. Environ. Pollut. 1019 - 34
RIDOUT PS and JONES HR (1988) Determination of trace elements in marine reference materials of Lobster Hepatopanceas (TORT - 1) using inductively coupled plasma mass spectrometry. Analyst 113 $1383-1386$

SAKAO SY, OGAWA Y and UCHIDA H (1999) Determination of trace elements in seaweed samples by inductively coupled plasma mass spectrometry. Anal. Chim. Acta 355121 - 127.

SKIDMORE JF (1964) Toxicity of zinc compounds to aquatic animals with special reference to fish. Q. Rev. Biol. 39227 - 248.

SPEAR PA (1981) Zinc in the Aquatic Environment: Chemistry, Distribution and Toxicology. National Research Council of Canada, Associate Committee on Scientific Criteria for Environmental Quality. Ottawa. Report NRCC No. 17589.

WATLING RJ and WATLING HR (1983) Trace metal surveys in Mossel Bay, St Francis Bay and Algoa Bay, South Africa. Water SA 957 - 62. 